\title{
Impact of English Language Proficiency on the Job Grabbing Process of Engineers in Nepal and the Other Countries: A Bird's Eye View
}

\author{
Rup Narayan Shrestha ${ }^{1}$, Jai Raj Awasthi ${ }^{2}$, Bharat Raj Pahari ${ }^{3}$ \\ ${ }^{1}$ Depatment of Science and Humanities, Pulchowk Campus, Institute of Engineering, TU, Nepal \\ ${ }^{2}$ University Campus, Tribhuvan University, Kathmandu, Nepal \\ ${ }^{3}$ Institute of Engineering, Tribhuvan University (TU), Kathmandu, Nepal \\ Corresponding author: rupnarayan_sth@hotmail.com
}

Received: Dec 12, 2017

Revised: Jan 8, 2018

Accepted: Jan 15, 2018

\begin{abstract}
This paper presents the findings of a research carried out on the impact of English language proficiency on the job grabbing process of the engineers in Nepal and a few other countries. Based mainly on the review of literature that were available in the internet websites, this paper sheds light on the facts that the English language proficiency is extremely important for the global engineers today. It reveals that the ability to communicate in English efficiently in their workplace is of paramount importance for engineers not only in Nepal but also in the other countries. In the present day context, the employers want to hire merely those candidates who possess sufficient proficiency in English.
\end{abstract}

Key words: Engineers, English, language, proficiency, jobs, employers

\section{Introduction}

At present, Engineering is one of the most popular and most demanding professions all over the world and today's engineers need to work with the co-workers and employers of diverse linguistic, ethnic and cultural background. For being able to communicate efficiently with the people of diverse linguistic background, they are required to possess sufficient proficiency in a common tongue which can be shared equally by all. For this purpose, English which is known as the most popular international language used commonly all over the globe can be the best choice. Considering this fact, the employers involved in most of the engineering companies and organizations expect their employees to possess the expected level of English language proficiency. In the present research, an attempt has been made to explore impact of the English language proficiency on the job grabbing process of engineers in the context of Nepal and a few other countries including India, China, Japan, Malaysia, Thailand, Saudi Arabia, Bahrain and Korea respectively through the review of existing literature available in the Internet websites.

\section{Methodology}

The present research is based primarily on the secondary source of data particularly literature review. During this research, the literature available in the Internet websites were reviewed taking 
down the most relevant ideas, data and details. Those ideas, data and details were analyzed and interpreted leading to some logical conclusions.

\section{Literature Review}

\subsection{Language and Human Communication}

Language is often defined as a means of human communication. We communicate with each other with the help of language. No other creatures except human beings in the world can use languages as efficiently as human beings do. It is due to our ability to speak language and communicate our thoughts, feelings and experiences that we have been able to prove ourselves as the superior beings in many respects to any other creatures that exist in this universe. Widdowson [19] rightly remarks "Language seems to be a feature of our essential humanity which enables us to rise above the condition of mere brutish beings, real or imagined" (p.4).

As we can use language as a means of communication and interchange our expressions so as to share our thoughts, emotions, pains and pleasures making it possible to cooperate and get our problems solved, we stand out quite distinctly amidst the crowd of numerous creatures in this world. According to Trask [18]"... human language is arguably the single most remarkable characteristic that we have, the one that most truly sets our species apart" (p.1).

Language is of vital importance for human communication and existence. If we had not been able to use language for communicating with the other human beings like ourselves, it could not have been possible for us to survive in this world as we always need sympathy, care, love and co-operation from others every moment, we fall victim of diseases and problems that might occur unexpectedly in our life, Widdowson [19] most appropriately puts it:

... Language certainly figures centrally in our lives. We discover our identity as individuals and social beings when we acquire it during childhood. It serves as a means of cognition and communication: It enables us to think for ourselves and to co-operate with other people in our community. It provides for present needs and future plans and at the same time carries with it the impression of things past (p.3).

Since we have languages and the ability to use it for Communication, it has been possible for us to solve not only the problems we have encountered at present, but it also has enabled us to think about future, make plans for it and even to share our experiences and impressions of the past. It is our language that has uplifted us from the dust and has helped us to attain what we have had as human beings of the present era of 2st century. It is quite relevant to cite the remarks of Trask [18] who states, "Without language, we could hardly have created the human world we know. Our development of everything from music to warfare could never have come about in the absence of language" (p.1).

\subsection{English Language and its Popularity}

The English language has no longer remained the language of United Kingdom or the United States of America in the present context of globalization. According to Rajwani [14], "English, a west Germanic Language spoken originally in England, is now the most widely used language in the world" (p.38). As the horizon of communication is expanding wider and wider day by day, the English language has also spread out its reach. At present, this language has gained the status of world language. In other words, it has scaled the lofty height of the global language. In 'The 
history of English' given in Wikipedia [20] it has been stated, "On almost any basis, English is the nearest thing there has been ever to a global language" (p.2).

Compared to other languages that exist all over the world, English language has many reasons to occupy the prestigious status of a global language. One of them is that this language has spread worldwide more than any other language in the history of human civilization. Another one is that it pervades various fields. Justifying its status as a global language, Wikipedia stresses, "Its worldwide reach is much greater than anything achieved historically by Latin or French, and there has never been a language as widely spoken as English. Many would reasonably claim that, in the field of business, academics, science, computing, education, transportation, politics and entertainment, English is already established as the de facto lingua franca" (p.2).

It is very appropriate to use the term 'global language' for the English language because of its features like richness and the depth of vocabulary, its flexibility, simple grammar, simple spelling and pronunciation, its cosmopolitan character, conciseness, absence of coding for social difference (e.g formal, informal) and quality of English literature. Rajwani [14] stresses, "It is a language which is rich in language, literature-humanistic, scientific and technical" (p.38).

It will prove to be an unwise decision to give up English. If anyone makes a decision to remove English from any teaching learning situation especially academic programs, it will prove not only short-sighted decision but it will also prove very costly for the entire nation as they will be pushing their nation backward forcing the future generations to live a primitive life cutting them off from the other parts of the world deprived of all the knowledge of the latest scientific, technological, political and cultural development citing the report of Radhakrishnan University Education Commission, Rajwani [14] remarks, "If under sentimental urges we give up English, we would cut ourselves off from the living stream of ever growing knowledge" (p.38).

At present, the popularity of English has crossed the boundary of the nations where this language is spoken as native language. It has begun to be used more in the other countries for wide-ranging fields than in the countries in which it is spoken as native language. Pointing out this situation, Rajwani [14] states, "It is an international language of diplomacy, science, technology, banking, medicine, aviation, UN and NATO ARMED Forces, Engineering, Tourism etc." (p.40).

\subsection{English in Engineering Communication}

English is excessively used in the field of engineering communication. It is almost impossible to imagine engineering communication without English. Renukadevi [15] remarks, "In the whole world of engineers, English has become the predominant language for communication" (p.52). The relationship between the English language and engineering is very intimate. They are so much interlinked that it is really hard to deal with them in isolation. In other words, the relationship between these two is very similar to that of nail and flesh. One of the reasons why the English language and the engineering have such an intimate relationship is that engineering itself is a subject of international nature and engineers trained in one country need not confine them to that particular nation alone. Since their skills and knowledge can be equally useful to the other nations, they can be hired by any international engineering companies. When they join an international company, they need to work with the co-workers and the employers whose native language may be different from theirs. At this particular case, they need sufficient proficiency in an international language like English Renukadevi [15] rightly remarks."...proficiency in communicative English is very essential for an efficient engineer who has sound technical background to interpret the technical 
facts in the universal language which everyone in any corner of the world can understand" (p.51).

To be a highly successful engineer, one needs to possess high level competence in communicative proficiency. Just the knowledge to mathematics, science and engineering is not sufficient for this. They should be able to communicate in a most effective and efficient manner to make their coworkers, boss and partners convinced with their ideas and plans. Just the knowledge of mathematical calculations and scientific or engineering experiments do not suffice. They are required to have a really efficient communicative talent for the successful handling of their jobs and responsibilities. Renukadevi [15] further adds, "The criteria to be successful engineer depends not only on the ability to perform calculations and experiments, as in most other jobs, but mainly based on the ability to present his innovative, creative ideas convincingly" (p.51).

Even when they complete their study and acquire degrees in engineering, the graduates need English for handling their jobs in their workplaces. English is generally used as an official language and they need to use it for their official communication. Renukadevi [15] stresses, "After graduation too, English takes its prominence because it is used in work places global wide"(p.51).

\subsubsection{English for Interpersonal Communication in Engineering}

Engineers need to work in groups. For working in groups, they need communicative skills in a language of common use. English is the only most appropriate language for them in this particular case as it is understood and spoken by a large number of people in almost every nook and corner of the world. As a language of common use, the English language may play a vital role in making the interpersonal communication between the engineers of different nationalities, their co-workers, and their boss possible. For this, engineers need to possess good command over English. Mohapatra [11] suggests. "English is the medium of interpersonal communication in the corporate world and therefore having good command on English language has become even more crucial" (p.22-23).

Without the ability to communicate with each other in a most convincing manner using the language of common use like English, it is quite impossible for them to perform their work successfully. In order to gain success in their project, engineers have to share their ideas, experiences, problems, as well as the ease and difficulties they have come across while trying to accomplish their work. To win the support of other co-workers while working in collaboration with them, leading them to the successful accomplishment of their project, they need to do all these things only when they can hold interpersonal communication through a common tongue effectively. Mohapatra [11] appropriately remarks, "Engineers usually work in groups and this very nature of their work demands mutual cooperation and effective interpersonal communication within and outside the organization in order to understand and co-ordinate with co-workers and accomplish their projects" (p.23).

\subsubsection{English Language for Engineering Career in Nepal}

The history of English language and its teaching and learning in the field of engineering education dated back to the inception of the Institute of Engineering itself. Right from the beginning of Engineering education, English was incorporated in the curriculum designed for both the Intermediate and Bachelor's Level. Though Intermediate level or Diploma level in engineering education has already been phased out recently, Bachelor's level still persists and English is one of the compulsory subjects taught there. At present, there is the English course of 125 marks including both theoretical and practical portions. The theoretical portion carries 100 marks and the practical portion carries 25 marks respectively. 
On the basis of the evidences of inclusion of English as one of the compulsory subjects up to the Bachelor's level in engineering curriculum, it is quite obvious that the English language teaching and learning has been given the some priority in the engineering education in Nepal. There are some pertinent reasons for incorporating English as a compulsory subject in engineering education in Nepal. There are some practical utilities of English in the field of engineering education in our country.

\subsubsection{English for Library Use}

As a large number of textbooks as well as reference books that the students of engineering need to read in order to enrich their knowledge related to their core subjects are available in the libraries and resource centers published in the English language, they need to possess at least the working knowledge of English to enable themselves to read, understand and get information from. Malla [10] points out:

... for a vast majority of the college and university-going population of Nepal, English is necessary mainly as a library language - language to have an access to textbooks, lectures and journals, on the one hand, and as a language to express one's thoughts and ideas in written, academic exercise on the other (p.16).

Without the knowledge of English language, it may be quite difficult or rather impossible for the students of advanced level engineering like Bachelor's level to acquire necessary information they need for enabling them to tackle the problems in their examinations which generally take place at the end of the academic year or semester.

\subsubsection{English for Examination}

The medium of examination in engineering in Nepal is English. The exam papers or the questions are set in the English language. To be able to understand those questions, the students of engineering need the knowledge of the English language. Those who lack sufficient proficiency in English will neither be able to understand the questions nor can they answer them properly. In such a case, even though the students possess sufficient knowledge of their engineering subjects, they fail or cannot secure satisfactory marks in the exam simply because of lack of their English language proficiency.

\subsubsection{English for Taking Notes}

Teachers of engineering subjects use the English language as their medium of classroom instruction while delivering lectures, explaining and demonstrating things to the class. The students are required to take down their class notes while listening to the teacher's lecture or demonstration and explanation for the preparation of their examinations that are held toward the end of the academic session. The students who lack sufficient command of English are sure to face a problem while trying to take down notes of their teacher's lectures.

Not only taking down notes while listening to the teacher's lectures, the English language is equally common in taking down notes from books, journals, articles and reports which they are supposed to read for the preparation of their exams or for reviewing the literature available in order to acquire some necessary philosophical or theoretical idea about the issue or subject on which they are preparing themselves for writing reports, proposals, projects and research articles. 


\subsubsection{English for Giving Talks/ Oral Presentations}

The students of engineering are usually involved in oral presentations. Since, they have the practical portion of 25 marks in their English syllabus, the part of their practical work involves giving oral presentations regularly. For giving oral presentations, they are required to possess sufficient proficiency in both spoken and written English as giving presentation involves planning, preparing and presenting it. Therefore, they need to get involved in a collaborative task of writing notes followed by giving oral presentations.

\subsubsection{English for Publishing Research Findings}

Engineering is the field in which academic activities such as research and experiments are continually taking place. Engineers are regularly involved in researches on various issues related to their area of study and work. When they carry out researches, conduct experiments and find out facts, they may want to inform the public as well as the concerned audience about their findings. For publishing their research findings, they write reports seminar papers or research articles.

In order to publish their research reports, seminar papers and research articles in the national or international journals the only international language they may opt for is English. English is widely used for publishing research documents as it is the language of common use in the field of science and technology. Malla [10] stresses, "As the language of science and technology, effective acquisition of the English language is going to be a primary prerequisite for the promotion of technical education" (p.24).

Not only in Nepal, English is used for the publication of research documents, like reports, research papers, and seminar paper all over the world no matter whether it is a developed or under-developed country. Even in the world's topmost industrialized countries which have made tremendous progress in their scientific and technological innovations, English is used for this purpose. According to Malla [10], "It so happens that even in the most advanced countries of the world, such as Sweden and Russia more than $80 \%$ of scientific researches are published in the English language. Even in a country as affluent as Japan is confronting the problem of market for expensive books produced in Japanese translation" (p.24).

\subsubsection{English for the Execution of Jobs}

Despite the fact that Nepal is very rich in her national languages spoken by the people belonging to various ethnic and communal groups all over the nation, there is no single national language sufficiently developed in terms of scientific and technological communication. For simple 'inter' or 'intra' official communication, the most commonly used official communication is English. Pointing to this situation, Malla [10] remarks "... had Nepali been adequate for transmission of science and technology and for international communication, there would have been no functional need for learning English" (p.12).

\subsubsection{English for Further Studies}

Majority of the engineering students prefer going abroad for further studies in the affluent and advanced countries like the USA, Germany, Denmark, Sweden and United Kingdom with a hope that they would have better exposure there and better trainings in their respective fields. From the very beginning of the process they start for submitting their application till they complete their 
study in those foreign universities, they need to use the English language as the sole medium of communication. Malla [10] states, "All that an average undergraduate needs to acquire in English is a certain level and certain kind of language so that the university graduate could use his command of English as a means of further the end of his key subjects" (p.4).

\subsection{English Language Proficiency for Job Grabbing Process of Engineers}

\subsubsection{Nepal}

The importance of the English language for the engineers especially for seeking and grabbing the job does not need to be magnified. English is the only medium of communication for them so far as their official or organizational communication is concerned. Whether it is for writing their letter of job application or publishing their reports or proposals, they use English. Nepali language is used just for correspondence with the local government. English language proficiency is one of the most essential pre-requisites for being offered job at any engineering company both within and outside Nepal. While passing through the selection procedures as an aspiring candidate of the post of engineer, they have to take written examinations in English medium. During the interview which takes place after they get through the written examinations also, they need to attend interview in English and their proficiency of the oral skill in the English language is tested there.

The interviewers will take their fluency and the command of the English language into account during the interview. Those candidates who have good command of English have a stronger chances of being offered the job, while those candidates whose command of the English language is felt to be very fragile are sure to be screened. Giri [7] states, "Some believe that the ability to use English is a prerequisite for achieving success in life" (p.197). Because English is the medium of international communication, academic activities like publication of academic works such as research documents, the proficiency of this language certainly enables people to be better exposed and knowledgeable. It helps them to gain success in their academic fields as well as in job markets. Giri [7] stresses, "People who know English are more exposed, more knowledgeable and therefore, more successful in life than those who do not. Without English, there is no academic or occupational future" (p.197).

As engineers are the bearers of knowledge of the world's latest technology, they need to maintain worldwide contact and communication. To help them fulfil this goal, knowledge of English is the only possible vehicle for them. Malla [10] points out, “... English has almost solely been our medium of international contact, exposure and communication" (p.23).

The knowledge and ability to use the English language efficiently is a must for the engineers in Nepal for the successful execution of their jobs and responsibilities as engineers. It is rather difficult for an engineer to move ahead without sufficient proficiency of the English language in today's context. Agrawal [1] states, "Without proper and adequate use of the engineering professional communicational skills of the English language in a country like ours, no engineer can move smoothly in his/her profession" (p.18).

\subsubsection{India}

India is one of the largest democratic nations in the modern world and she is making rapid progress in the field of science and technology. A large number of world's topmost engineering institutes including Indian Institute of Technology (IIT) are located in India. From these renowned institutes, 
thousands of engineers are being produced every year. The quality of the products of these institutes is also being tested all over the world as many of them have been hired by the international scientific and technical organizations all over the world.

With the rapid pace of growth in the number of engineering manpower produced from the institutes in India, their job markets are also widening day by day. At the same time, they are growing more and more challenging as the rate of the problem of unemployment is also increasing in this sector. In India, English is used as a medium of official communication. There is high demand of engineers with good command of the English Language. Many engineering graduates in India are deprived of job opportunities simply because of lack of sufficient proficiency in the English language.

Devi [5] points out, "Research has revealed that there is a serious unemployment problem amongst graduates due to the lack of English skills and competency" (p.18). In India, the use of English as a vehicle of communication in engineering is gaining popularity at a rapid pace. For being employed in any engineering company, the aspiring candidates are required to possess sufficient proficiency in the English language. Knowledge of English and ability to communicate in English is one of the basic pre-requisites for joining any engineering company. Devi [5] remarks, "English language is considered as a stepping stone along the pathway to securing employment" (p.18).

The employers in modern India seek the employees for their engineering companies with high level proficiency of the English language. For being employed, the engineers need to meet the demand of the English language proficiency as pre-requisite. According to Clement and Murugavel [4], "English communication skill is one of the most important employability requirements in modern India" (p.16) Those candidates who are joining engineering companies are expected to be capable of expressing their views in English clearly without any halts and hesitations. Clement and Murugavel [4] stress, "Candidates are expected to voice their ideas in English without any ambiguity and fear" (p.116).

Since there is ever increasing demand of the candidates who can communicate in English well, many employers' companies have been attempting to tempt the candidates by offering them more salaries and wages. Batra [2] mentions, "The book 'Future and English in India' and research by World Bank and Florida and Connecticut University reveals that $13 \%$ to $34 \%$ increase in wages results with better communication in English" (p.1).

\subsubsection{China}

China is emerging as a super-power in the present day world especially in the field of economy, industry and technology. The pace of economic and technological growth and expansion is very rapid in China. With the fast rate of acceleration in the modernization, and industrialization, the use of English is also increasing. The history of English language teaching and learning in China dates back to the early seventeenth century. It has been a fairly long time since China introduced English in her territory. As Bolton [3] points out,

... the language (English) has had a lengthy, complicated and often forgotten history that began in the early seventeenth century with the first documented account of linguistic and central contact, through the era of Chinese pidgin English from the early eighteenth century to the recent past, to the Republication period between 1911 and 1949, when English was widely learnt in missionary schools and the thirteen Christian Colleges, many of which have become leading industries in 
contemporary China (p.2).

The popularity of English is increasing in the modern Republican China at a faster rate. The open door policy adopted by the Chinese Government has opened the doors of employment opportunities to its youths by expanding its volume of industries and economic growth. China has strengthened her bond of relationship with the other nations in the world especially in the area of trade, commerce and culture. In the present context, English prevails all over China and has its importance deeply-rooted in every sector of the Chinese society. Bolton and Graddol [3] remark,

...More and more importance has been given to English after China carried out the policy of reform and opening up to the outside world in the late 1970s. And accompanying China's rise on the world stage in recent years are growing connections of commerce and culture with other countries, especially those developed English speaking countries. [...] The entire Chinese society attaches high importance to the English study as sometimes it even plays a vital role for a person who plans to pursue further education and seek a better career (p.1).

\subsubsection{Japan}

Japan is one of the leading nations in the field of science and technology, international trade and commerce. The Japanese technology has earned worldwide popularity in terms of quality. Quality and the Japanese products have been synonymous with each other now because the Japanese products have been highly trusted in quality, a slightly high price of those products matters very little for the customers. The customers are ready to pay the high price for the Japanese products because of their craze for quality.

The use of English as a medium of communication in the official context, trade and commerce has increased in the recent days though it was not so in the past. According to Neeley [12], "Hiroshi Mikitani, the CEO of Rakuten-Japan's largest online marketplace decided to mandate in March 2010 that English would be the company's official language of business" (p.1). Mikitani seems to have realized how important it is for the employees in his company to possess communication proficiency in an international language like English for the promotion and expansion of his company. He stated that employees would have to demonstrate competence on an international English scoring system within two years or risk demotion or even dismissal [12, p.2].

\subsubsection{Malaysia}

Malaysia is known for its rapid advancement in the economic field in the modern world economy. Once a very backward nation, Malaysia has attained tremendous economic growth within a short span of time in its history. Whenever people need to take the name of any nation which has made a great leap forward in the economic field in the modern world, they do not lag behind in citing the example of Malaysia.

Even in Malaysia, there is a great importance of English language proficiency for the young engineering graduates for obtaining employment. Kassim and Ali [8] state,

...the Malaysia Employers Federation (MEF, 2004) stated that engineering and science graduates were the most sought after graduates due to the proliferation of industries both in Malaysia and globally. However, many employers were hesitant to hire these graduates due to their poor proficiency in the language, although they 
were highly qualified academically (p.168).

For internal as well as external communication, organizations in Malaysia have given English the highest status especially for preparing official documents such as proposals, prospectus, reports and projects. As cited by Kassim and Ali [8], from their investigation, they found that apart from Portuguese, a great majority of the organizations used English for internal and external communications. They also reported that large organizations and industries involved in the study lay great emphasis on English and utilized it in a wide range of document types such as proposals, prospectuses, reports and projects [8], see p.168-182.

\subsubsection{Thailand}

Every nation in the world has its own language used as a common means of communication and Thailand is not an exception. Despite this, the English language has been given the highest priority in the official academic as well as technical communication in this country. In their research article written in the context of Thailand, Rajprasit et al. [13] stress, "commonly English language matters greatly in the global economy to professionals at both the national and international levels" (p. 27).

In the context of Thailand also, English language is of great significance not only for the professionals involved in the trade and tourism, commerce and communication, but also for the professionals like engineers as they need to communicate with the people of diverse nationalities, ethnicity, culture and language. It is quite appropriate to quote Rajprasit et al. [13] who remark, "Professionals, including engineers are expected to communicate effectively in English, even though they often use their mother tongue in everyday life" (p. 27).

In order to handle their jobs and responsibilities as engineers in a most efficient manner, Engineers in Thailand are also required to possess sufficient communication skill in English. Emphasizing on the necessity of the English language proficiency for engineers, Rajprasit et. at. [13] stress, "Engineers also have to deal with the tasks, which require more English for writing emails, minutes, reports, project proposal, business letters, memos, speaking with customers, reading, writing instructions, and receiving spoken instructions, etc." (p. 28).

\subsubsection{Saudi Arabia}

Saudi Arabia is also known as one of the fastest emerging economy in the modern world. The rate of economic and industrial expansion is astonishingly high in this country at present. As a fast emerging and advancing country, the pace of growth in the flow of foreign technicians and engineers is increasing at a faster rate there. Widely known as Muslim country with its majority of Arabian language speaking population, the importance of English language proficiency especially in the employees of technical and commercial fields such as engineering and business is soaring day by day. According to Ryhan [16], "In 2003, the Saudi Ministry of Education passed a law that mandates the teaching of English in the public schools starting from Grade 6. A year later, the teaching of English started in Grade 5" (Al-Jarf, 2008) 143-144.

\subsubsection{Bahrain}

Among the various employer gulf countries for the young engineering graduates all over the world, Bahrain is also one popular destination. Many young engineers produced from various engineering institutes in different parts and regions of the entire world prefer to go to this country for foreign employment for them. In this country also, the English language is found to be given the top 
priority for being hired or employed by any company there. According to Thomas et al. [17].

...Initial research within Bahrain, prior to establishment of the Polytechnic in 2008, found that industry had consistently identified 'poor English language capability' as one of a number of deficiencies in new graduates entering the workplace, alongside critical thinking, problem solving and group work (p. 2).

For promoting their business and increasing sales rate, the employers of the industries want to hire those employees who possess English language competency. Thomas et al. [17] point out, "During an internal review of English provision at the polytechnic in 2012, employer focus groups identified English competency at the Polytechnic as a 'unique selling point' to employees" (p. 2).

\subsubsection{Korea}

Korea is also known as one of the most popular destinations for the young people moving around in search of employment in the present day world. Young people from all over the world have now begun to choose Korea as their popular destination for foreign employment. Many graduates who have completed their engineering education are also found moving to Korea for employment. As Korea has grown as a meeting point for a significant number of young engineering graduates from various countries in the world, the only common means of communication for them is English. Expressing his view in the context of Korea, Kim [9] states, "Engineers all around the world would find themselves use English for some aspect of their job" (p. 45).

The Korean industries seek young graduates with English proficiency while hiring employees to work for them. Job is easier to obtain for those graduates who have studied or learnt practical English. According to Kim [9], "In a survey research, the industries answered 'Practical English or Language related subject' is the most useful subject to get a job among the Specialized General Curriculum subjects in the accreditation system" (p.45).

The employers want to hire those engineering candidates who are proficient enough in spoken English as they need to communicate with their co-workers, boss and employers who come from different socio-linguistic and cultural background. Kim [9] suggests. "English for engineering students with speaking skill much focused is needed" (p.47).

\section{Conclusion}

From the in-depth study of the existing data that could be availed of, we conclude that today's global engineers are required to have sufficient level of English language proficiency for being offered the job at the national and international engineering companies and organizations. It has also revealed that only those engineering graduates who possess the sufficient level of proficiency in English language can grab the job opportunities. Therefore, engineers of today need to strive to equip themselves up with the expected level of English language proficiency in order to grab employment opportunity all over the world.

Acknowledgements: I would like to extend my cordial gratefulness to Prof. Dr. Tri-Ratna Bajracharya, the Dean, IOE, TU, Dr. Niranjan Prasad Sharma, the Assistant Dean, IOE, Prof. Dr. Shailendra Kumar Mishra, Prof. Dr. Ram Kumar Sharma, Prof. Dr. Bhadra Prasad Pokhrel, Prof. Dr. Binod Kumar Bhattarai and Dr. Gyan Bahadur Thapa from Department of Engineering Science \& Humanities, Pulchowk Campus, IOE. 
234 Impact of English Language Proficiency on the Job Grabbing Process of Engineers in Nepal...

\section{References}

[1] Agrawal S (2016), Professional English Communication for Engineers in Nepal. India: Journal of Advanced Academic Research (JAAR), 3(2) : 14-21.

[2] Batra VK (2013), English Communication: An Employability Skills. India. Global Competence, Panipat, Haryana.

[3] Bolton K and Graddol D (2012), English in China Today. www.ntu.edu.sg.

[4] Clement A and Murugavel T (2015), English for Employability: A Case Study of the English Language Training Need Analysis form Engineering Students in India. India: Canadian Centre of Science and Education.

[5] Devi MR (2016), English for Employment of Indian Students, Journal of English Language and Literature, 3(1).

[6] e-paper (http://paper.hindustantimes.com/epaper/viewer.aspx). India, 2017.

[7] Giri RA (2014), Changing Faces of English: Why English is not a Foreign Language in Nepal. Journal of World Languages, Routledge, Taylor \& Fraacis Group. 1(3) : 192 - 209.

[8] Kassim H and Ali F (2010), English Communicative Events and Skills needed at the Workplace: Feedback from the industry. Malaysia: Science Direct.

[9] Kim HH (2017), A Research on the English for Engineering Students Course Based on Needs Analysis in Korea. Korea: Kongju National University, hhkim@kongju.ac.kr.

[10] Malla KP (1977), English in Nepalese Education. Kathmandu: Ratna Pustak Bhandar.

[11] Mohapatra M and Satpathy S (2014), English for Engineering Students: A Study of the Teachinglearning System in Indian Context. IOSR. Journal of Humanities and Social Science, 19(9) : $22-27$.

[12] Neeley T (2012), Global Business Speaks English. Harvard Business Review. Cross-Cultural Management. Twiter:@tsedal.

[13] Rajprasit K et al. (2017), Use of the English Language Prior to and During Employment: Experiences and Needs of Thai Novice Engineers. Thailand: Global Journal of Engineering Education, 16(1) : 27-33.

[14] Rajwani HG (2012), English as a Tool for Employment and Employability. India: International Multidisciplinary e-Journal, 1(9) : 33-44.

[15] Renukadevi D (2013), Communicative English: Why it is Essential to Emerging Engineers; The challenges and Remedies. India: Research India Publications.

[16] Ryhan E (2014), The Role of the Impact of English as a Language and Medium of Instruction in Sndi Higher Education Institutions: Students-Instructions Perspectives. Study in English Language Teaching. 2(2), www.scholink.org/ojs/Index.Php/Selt.

[17] Thomas et al. (2017). English Communication Skills for Employability: The Prospective of Employers in Bahrain. Learning and Teaching in Higher Education: Gulf Perspectives, 13(1): $1-17$.

[18] Trask RL (2003), The Uniqueness of Human Language: Language, The Basics.

[19] Widdowson HD (2003), The Nature of Language Linguistics. USA: Oxford University Press.

[20] Wikipedia, 2017. 